\title{
Sudden 'cure' of type two diabetes due to pancreatic insulinoma: A case report
}

\author{
CONSTANTINOS NASTOS $^{1}$, DIMITRIOS GIANNOULOPOULOS ${ }^{1}$, DIONYSIOS DELLAPORTAS ${ }^{1}$, \\ MARIA MIZAMTSIDI ${ }^{2}$, NIKOLAOS DAFNIOS ${ }^{1}$, NIKOLAOS KLONARIS ${ }^{2}$, \\ NIKOLAOS KALOGERIS ${ }^{2}$ and ANDROMACHI VRYONIDOU ${ }^{2}$
}

${ }^{1}$ Second Department of Surgery, Endocrine Surgery Unit, National and Kapodistrian University of Athens, School of Medicine, Aretaieion University Hospital, 11528 Athens; ${ }^{2}$ Department of Endocrinology and Diabetes,

Hellenic Red Cross Hospital, 11526 Athens, Greece

Received January 22, 2019; Accepted July 5, 2019

DOI: $10.3892 /$ mco.2019.1957

\begin{abstract}
Insulinomas are rare tumors of the islet cells of the pancreas and are the most common cause of endogenous hyperinsulinism. Although they usually present with symptoms of hypoglycemia, sometimes they can have vague symptoms. We present the case of a 62-year-old diabetic female who was diagnosed with a large insulinoma after being investigated for the 'cure' of her diabetes. We also review the literature regarding insulinomas in patients with diabetic. A 62-year-old, obese woman with type 2 diabetes mellitus was initially investigated for an unexplained normalization of her blood glucose levels after the cessation of antidiabetic medication due to an episode of severe hypoglycemia. She remained without antidiabetics for three months maintaining normoglycemia, and thereafter, she started experiencing frequent but less severe hypoglycemic episodes. She did not change her diet habits or level of activity and did not lose any weight. The patient underwent further investigation with a supervised $72 \mathrm{~h}$ fasting test, which resulted in the biochemical diagnosis of endogenous hyperinsulinism. Imaging studies revealed the presence of a large insulinoma in the head of the pancreas. Finally, the patient underwent a pylorus preserving Whipple procedure, which reversed the aforementioned 'normalization' of glucose levels and the underlying diabetes mellitus reappeared. Insulinomas are rare tumors causing hypoglycemia. Even more rarely are found in diabetic patients, making the diagnosis more challenging and probably delayed, as the symptoms are masked by the presence of diabetes, thereby leading to a more advanced disease diagnosis.
\end{abstract}

Correspondence to: Professor Constantinos Nastos, Second Department of Surgery, Endocrine Surgery Unit, National and Kapodistrian University of Athens, School of Medicine, Aretaieion University Hospital, Vasilissis Sofias 76, 11528 Athens, Greece E-mail: kosnastos@yahoo.gr

Key words: insulinoma, large, diabetes mellitus, cure, malignant

\section{Introduction}

Insulinomas are rare neuroendocrine tumors with an incidence of three to ten cases per million per year (1). Approximately $90 \%$ of insulinomas are benign and the remaining $10 \%$ are malignant, with lymph node or liver metastases often present at the time of diagnosis (2). Hypoglycemic symptoms are the usual manifestations of these tumors, although patients can be misdiagnosed as having cognitive, neurologic and psychiatric disorders. Insulinomas are even rarer in patients with diabetes. There are no formal epidemiologic studies of the incidence of the condition in this population, and only a few cases have been reported in the literature (3). The diagnosis is challenging, as many of those patients never develop hypoglycemic symptoms or do so only when the disease is advanced. In addition, hypoglycemic episodes of non-endogenous etiology are very common in diabetic patients.

In this report, we present a female patient with type 2 diabetes mellitus (T2DM) who was finally diagnosed with a large insulinoma after being investigated for an unexpected 'cure' of her diabetes.

\section{Case report}

A 62-year-old obese, diabetic female diagnosed with T2DM 15 years earlier and treated with metformin and vildagliptin since then suddenly developed episodes of hypoglycemia. She reported confusion, lack of consciousness, blurred vision and weakness. The symptoms were unrelated to meals. Although metformin and vildagliptin do not typically cause hypoglycemia, they were discontinued. Her blood glucose levels remained normal despite the cessation of antidiabetic medication and milder hypoglycemic episodes continued. The patient reported no weight loss [body mass index $(B M I)=43$ ], no change in her dietary habits, apart from developing an increased appetite for sweeteners, and no alteration in physical activity.

Due to the persistence of her symptoms, the patient underwent a supervised $72 \mathrm{~h}$ fasting test. She developed symptoms of hypoglycemia within $58 \mathrm{~h}$ with serum glucose concentration at $34 \mathrm{mg} / \mathrm{dl}$, insulin plasma concentration at $10 \mu \mathrm{IU} / \mathrm{ml}$ 

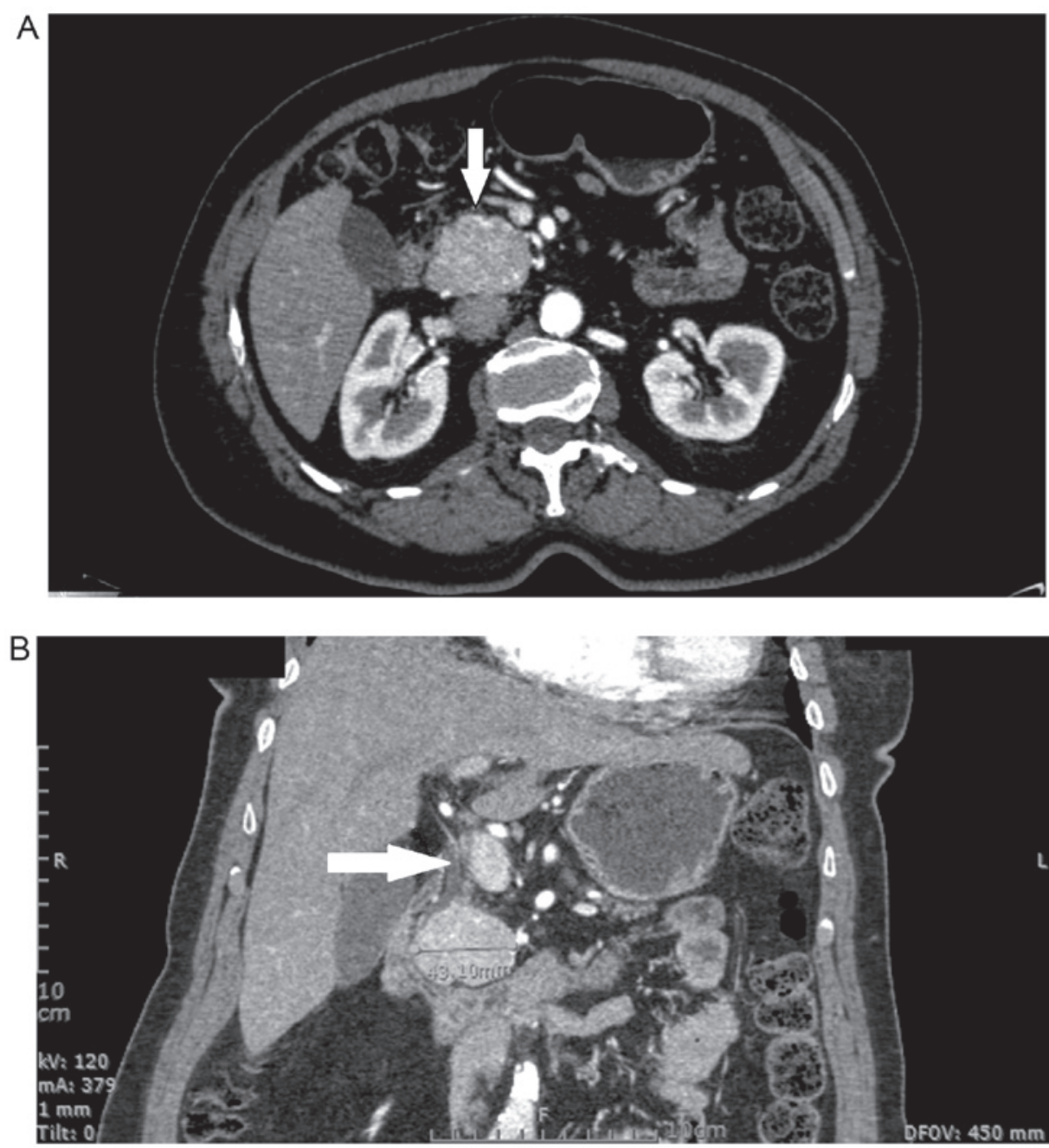

Figure 1. Computed tomography scan of the abdomen with the pancreatic protocol showing: (A) A lesion of the head of the pancreas (arrow) with increased vascularity in the arterial phase and (B) the lesion in contact with and displacing the common bile duct (arrow).

and C-peptide concentration of $5.7 \mathrm{ng} / \mathrm{ml}$. These values were over our institution's threshold ( $>6 \mu \mathrm{IU} / \mathrm{ml}$ for plasma insulin, $>0.6 \mathrm{ng} / \mathrm{ml}$ for C-peptide and $<45 \mathrm{mg} / \mathrm{dl}$ for glucose) and established the biochemical diagnosis of endogenous hyperinsulinemia.

Moreover, a pancreatic computerized tomography (CT) scan with significant contrast enhancement during the arterial phase and without distention of the pancreatic duct revealed a round, solid $4.8 \times 3.6 \mathrm{~cm}$ lesion, with a few calcifications in the head of the pancreas (Fig. 1A). These findings were compatible with the diagnosis of a neuroendocrine tumor of the pancreas. No other lesions were found in the liver, thus excluding metastases. Indium-111 radiolabeled octreotide scintigraphy was also performed and showed an area of significant avidity in the pancreas. Brain CT was negative for pituitary pathology, and calcium levels were normal. Serum CA 19-9 levels were within normal range, and serum insulin antibodies were negative.

Exploratory laparotomy was negative for metastatic disease, and multiple lesions were assessed with intraoperative ultrasound. An enlarged hepatoduodenal lymph node was sent for frozen section and was negative for malignancy. The tumor was in contact with both the intra-pancreatic bile duct and the pancreatic duct, so tumor enucleation was not possible
(Fig. 1B). With the tumor larger than $2 \mathrm{~cm}$ in diameter, malignancy could not be excluded, therefore the patient underwent a pylorus-preserving pancreatoduodenectomy. As the pancreatic duct was not distended and the pancreatic parenchyma was very soft a jejunopancreatic anastomosis did not take place and the remaining pancreas was ligated.

Pathology report confirmed the diagnosis of a grade I insulinoma $(4.5 \times 4 \times 3.5 \mathrm{~cm})$ with low mitotic index and a Ki67 proliferation index of approximately $1 \%$, positive for chromogranin and synaptophysin, negative for CK19 and PgR and without surrounding tissue or lymph node infiltration.

Postoperatively, serum glucose levels increased significantly ranging from 162 to $210 \mathrm{mg} / \mathrm{dl}$, and normoglycemia was achieved with continuous intravenous insulin infusion. This was discontinued on the seventh postoperative day when oral intake was tolerated. The patient restarted her antidiabetic medication and was prescribed oral pancreatin. She was discharged on the fourteenth postoperative day. She continued with oral antidiabetics to control blood glucose levels and did not report any symptoms related to hypoglycemia at her one-year follow-up appointment. At that follow-up, she presented with a significant weight loss and a decrease in her BMI to 30.2. This was attributed mainly to the pancreatoduodenectomy procedure and to the fact that the 
pancreatic remnant was not anastomosed to the intestine. This led to exocrine pancreatic insufficiency despite the pancreatic enzymes which were prescribed to the patient. Serum glucose was $148 \mathrm{mg} / \mathrm{dl}$ in accordance with here T2DM and c-peptide levels were $1.7 \mathrm{ng} / \mathrm{ml}$.

\section{Discussion}

Insulinomas are rare pancreatic neuroendocrine tumors; symptoms include hypoglycemia. Diagnosis can be challenging as typical neuroglycopenic symptoms and hypoglycemia can be mistaken for other pathology. Of additional interest in the case described above, our patient experienced an unexpected resolution of her diabetes.

There are very few reports in the literature of insulinoma in diabetics. Insulinomas do not always produce sufficient amounts of insulin to result in symptomatic hypoglycemia (4). Moreover, patients with T2DM have insulin resistance, which may explain the lack of typical hypoglycemic symptoms. Obesity, conversely, increases insulin resistance as part of the metabolic syndrome, and hyperinsulinism causes weight gain which in turn increases insulin resistance. Insulinomas can easily be missed in these patients as the reduced blood glucose can be attributed to other factors such as excessive exogenous insulin, antidiabetic medication, strenuous exercise, fasting and inadequate diet. Insulinoma in type 1 diabetic patients have been described even more rarely (5).

With respect to insulinomas tumorigenesis, the molecular pathogenetic mechanisms include alterations in cell physiology resulting from the accumulation of genetic or epigenetic alterations. These alterations lead to uncontrolled cellular growth and evasion of programmed cellular death (apoptosis), unlimited replication potential, angiogenesis and possible tissue invasion and metastases (6). The primary mechanisms identified in insulinoma oncogenesis involve impaired menin molecular interactions (including cyclin-dependent kinase $[\mathrm{CDK}]$ inhibitor regulation such as p27 and p18), cell cycle deregulation through growth signals (overexpression of cyclin-D1 and Akt1 gene), insensitivity to anti-growth signals (inactivation of retinoblastoma protein gene-pRb and phosphatase with tensin homology gene-PTEN), resistance to apoptosis (deregulated expression of c-Myc, surviving and Bcl-2 gene), unrestricted proliferation potential, angiogenesis and tissue invasion (6). More specifically, over-activation of the phosphorylated mechanistic target of the rapamycin (p-mTOR) signaling pathway has been found in insulinomas, resulting in tumor formation commonly due to mutations of tumor suppressor PTEN gene and mutations in band 11q13 (Menin gene) (7,8). K-ras mutations have been linked with malignancy (9). CYR61 has also recently been found to be an oncogenic factor (10).

This clinical case and all other similar case reports in the literature pose clinical questions that cannot easily be addressed. Can diabetes be a disorder that can chronically stimulate $\beta$ cells of the pancreas and force them to proliferate into the formation of tumors? It was initially thought that pancreatic endocrine tumors were of hyperplastic origin rather than of primarily neoplastic origin (11). Based on this, it could be speculated that insulin resistance or chronic treatment with sulfonylureas may induce $\beta$ cell hyperplasia and/or over-activation and result in tumor formation (12). Functional $\beta$ cell hyperplasia has been shown in chronic hyperglycemia or insulin resistance when glucose levels are normal (13). $\beta$ cell hyperplasia has also been reported after bariatric surgical procedures and is usually related to dumping syndrome (14). Obesity has been proven to cause functional $\beta$ cell hyperplasia due to insulin resistance. In the same context, high lipid diet and a diet high in free fatty acids (FFA) may account for the compensatory upregulation of $\beta$ cell function in response to insulin resistance (15). Conversely, long-term exposure to FFA suppresses glucose-stimulated insulin secretion and has been suggested to result in impaired glucose metabolism, reduced insulin biosynthesis and $\beta$ cell loss (16). However, the progression from $\beta$ cell hyperplasia to insulinoma formation has been proven only in experimental models, not in human studies (17). More specifically, a multistep developmental sequence of insulinoma has been postulated in a Moloney murine sarcoma virus-simian virus-40 (MSV-SV40) large T transgenic mouse model. The sequence has been described as a transformation from nesidioblastosis to islet cell hyperplasia and dysplasia and finally to tumor formation (18). Conversely, patients with a reduction in the number of $\beta$ cells (as is the case in autoimmune type 1 diabetes and non-obese type 2 diabetes) could be thought to have a negative predisposition for developing insulinoma. A correlation, either positive or negative, between insulinomas and insulin-dependent diabetes has not been proven (19).

There are no reports of increased incidence of insulinoma in patients with diabetes compared to non-diabetics, as there are millions of diabetics worldwide and only a few cases of insulinoma in diabetics reported to date. However, our review of the literature interestingly revealed that reported cases insulinoma in patients with diabetes are rather more advanced when diagnosed. Therefore, it can be speculated that these tumors are underdiagnosed in patients with diabetes. Current literature suggests that insulinomas are malignant in $10 \%$ of cases (3). We found over 50 cases of insulinoma presenting in those with diabetes. Of these, five presented in patients with type 1 (5,20-22), and the remaining cases were diagnosed in patients with T2DM. In contrast to the malignancy rate in other patients, the incidence of malignancy in these reported cases was at least $25 \%(3,5,20,22-32)$. Additionally, although it is reported that $90 \%$ of insulinoma are typically less than $2 \mathrm{~cm}$ in diameter at diagnosis in other patients (3), among the cases describing insulinoma in diabetics, tumor size was $>2 \mathrm{~cm}$ in a significant proportion of patients $(3,12,20,21,23,33-36)$. Although this could be based on publication bias, this may be explained by the fact that insulinoma diagnosis is difficult in these patients and only those with more overt disease present with symptoms and receive a definitive diagnosis.

One could also argue that, in diabetic patients, endogenous hyperinsulinemia could be beneficial, especially in the absence of severe hypoglycemic symptoms. This would challenge the mainstream surgical therapy of insulinoma in this patient group. However, the surgical removal of insulinomas could be justified for three reasons. First, it is not possible to preoperatively determine whether an insulinoma is benign or malignant. Second, insulinomas do not secrete insulin in a physiologic pattern defined by blood glucose levels and therefore patients cannot achieve predictable glucose homeostasis (37). Third, high insulin levels have been associated with 
an increase in plasminogen activator inhibitor type-1 (PAI-1). This has been implicated as a determinant of atherogenesis and particularly of plaques prone to rupture, precipitating acute coronary syndromes (38).

In conclusion, insulinomas are rarely reported in patients with diabetes mellitus, possibly due to the masking of the disease by insulin resistance and the rare occurrence of episodes of hypoglycemia. Clinical suspicion is very important in order to make the diagnosis in these patients. Although diabetes mellitus appears to be resolved in these patients when they develop insulinomas, surgical management is still the mainstream therapeutic option.

\section{Acknowledgements}

Not applicable.

\section{Funding}

No funding was received.

\section{Availability of data and materials}

The datasets used and/or analyzed during the current study are available from the corresponding author on reasonable request.

\section{Authors' contributions}

$\mathrm{CN}, \mathrm{AV}$ and ND conceived and designed the study. DG and $\mathrm{NK}$ l performed the literature data collection and acquired the patient data and follow-up information. MM, DD, NK1 and $\mathrm{NKa}$ analyzed the bibliographic data and built the database with the patient's characteristics from all of the reported cases in the literature. DG, NKa and ND wrote the article. CN, AV, NKa and ND critically revised the article. All authors have read and approved the final version of this manuscript.

\section{Ethics approval and consent to participate}

Written informed consent was obtained from the patient.

\section{Patient consent for publication}

The patient gave written informed consent for the publication of this case report.

\section{Competing interests}

The authors declare that they have no competing interests.

\section{References}

1. Dadan J, Wojskowicz P and Wojskowicz A: Neuroendocrine tumors of the pancreas. Wiad Lek 61: 43-47, 2008.

2. Hirshberg B, Cochran C, Skarulis MC, Libutti SK, Alexander HR, Wood BJ, Chang R, Kleiner DE and Gorden P: Malignant insulinoma: Spectrum of unusual clinical features. Cancer 104: 264-272, 2005 .

3. Kamocki ZK, Wodynska NA and Pryczynicz A: Co-existence of insulinoma and diabetes: A case report. Oncol Lett 8: 1697-1700, 2014.
4. Doherty GM, Doppman JL, Shawker TH, Miller DL, Eastman RC, Gorden P and Norton JA: Results of a prospective strategy to diagnose, localize, and resect insulinomas. Surgery 110: 989-997, 1991.

5. Lablanche S, Chobert-Bakouline M, Risse O, Laverriere MH, Chabre $\mathrm{O}$ and Benhamou PY: Malignant insulinoma may arise during the course of type 1 diabetes mellitus: A case report. Diabetes Metab 41: 258-261, 2015.

6. Jonkers YM, Ramaekers FC and Speel EJ: Molecular alterations during insulinoma tumorigenesis. Biochim Biophys Acta 1775: 313-332, 2007.

7. Zhan HX, Cong L, Zhao YP, Zhang TP, Chen G, Zhou L and Guo JC: Activated mTOR/P70S6K signaling pathway is involved in insulinoma tumorigenesis. J Surg Oncol 106: 972-980, 2012.

8. Bhatti TR, Ganapathy K, Huppmann AR, Conlin L, Boodhansingh KE, MacMullen C, Becker S, Ernst LM, Adzick NS, Ruchelli ED, et al: Histologic and molecular profile of pediatric insulinomas: Evidence of a paternal Parent-of-Origin effect. J Clin Endocrinol Metab 101: 914-922, 2016.

9. Pavelic K, Hrascan R, Kapitanovic S, Vranes Z, Cabrijan T, Spaventi S, Korsic M, Krizanac S, Li YQ, Stambrook P, et al: Molecular genetics of malignant insulinoma. Anticancer Res 16: 1707-1717, 1996.

10. Huang YT, Lan Q, Ponsonnet L, Blanquet M, Christofori G, Zaric J and Rüegg C: The matricellular protein CYR61 interferes with normal pancreatic islets architecture and promotes pancreatic neuroendocrine tumor progression. Oncotarget 7: 1663-1674, 2016.

11. Heitz PU, Kasper M, Polak JM and Klöppel G: Pancreatic endocrine tumors. Hum Pathol 13: 263-271, 1982.

12. Sakurai A, Aizawa T, Katakura M, Sato Y, Kaneko G, Yoshizawa K and Hashizume K: Insulinoma in a patient with non-insulin-dependent diabetes mellitus. Endocr J 44: 473-477, 1997.

13. Weir GC and Bonner-Weir S: Islet $\beta$ cell mass in diabetes and how it relates to function, birth, and death. Ann N Y Acad Sci 1281: 92-105, 2013.

14. Ouyang D, Dhall D and Yu R: Pathologic pancreatic endocrine cell hyperplasia. World J Gastroenterol 17: 137-143, 2011

15. Stefanovski D, Richey JM, Woolcott O, Lottati M, Zheng D, Harrison LN, Ionut V, Kim SP, Hsu I and Bergman RN: Consistency of the disposition index in the face of diet induced insulin resistance: Potential role of FFA. PLoS One 6: e18134, 2011.

16. Cerf ME: Beta cell dysfunction and insulin resistance. Front Endocrinol (Lausanne) 4: 37, 2013.

17. Zumkeller W: Nesidioblastosis. Endocr Relat Cancer 6: 421-428, 1999.

18. Gotz W, Schucht C, Roth J, Theuring F and Herken R: Endocrine pancreatic tumors in MSV-SV40 large T transgenic mice. Am J Pathol 142: 1493-1503, 1993.

19. Weir GC: Non-insulin-dependent diabetes mellitus: Interplay between B-cell inadequacy and insulin resistance. Am J Med 73: 461-464, 1982

20. Gjelberg HK, Hoem D, Verbeke CS, Eide J, Cooper JG and Molven A: Hypoglycemia and decreased insulin requirement caused by malignant insulinoma in a type 1 diabetic patient: When the hoof beats are from a zebra, not a horse. Clin Case Rep 5: 761-768, 2017.

21. Oikawa Y, Katsuki T, Kawasaki M, Hashiguchi A, Mukai K, Handa K, Tomita M, Kabeya Y, Asai Y, Iwase K, et al: Insulinoma may mask the existence of type 1 diabetes. Diabet Med 29: e138-e141, 2012.

22. Svartberg J, Stridsberg M, Wilander E, Andersson DE and Eriksson B: Tumour-induced hypoglycaemia in a patient with insulin-dependent diabetes mellitus. J Intern Med 239: 181-185, 1996.

23. Abbasakoor NO, Healy ML, O'Shea D, Maguire D, Muldoon C, Sheahan K and O'Toole D: Metastatic insulinoma in a patient with type 2 diabetes mellitus: Case report and review of the literature. Int J Endocrinol 2011: 124078, 2011.

24. Ademoglu E, Unluturk U, Agbaht K, Karabork A and Corapcioglu D: Type 2 diabetes mellitus in a patient with malignant insulinoma manifesting following surgery. Diabet Med 29: e133-e137, 2012.

25. Atkinson AB, Buchanan KD, Carson DJ, Kennedy T, O'Hare MM, Sloan JM and Hadden DR: Insulinoma (apud cell carcinoma) in a diabetic. Br Med J 2: 1397-1398, 1978.

26. Campos-Olive N, Ferrer-García JC and Safont M: Malignant insulinoma in a patient with type 2 diabetes mellitus. Acta Endo Buc 6: 103-109, 2010. 
27. Ferrer-Garcia JC, Tolosa-Torrens M, Hernando-Melia C, Arribas-Palomar L and Sanchez-Juan C: Everolimus resolving hypoglycemia, producing hyperglycemia, and necessitating insulin use in a patient with diabetes and nonresectable malignant insulinoma. Endocr Pract 17: e17-e20, 2011.

28. Grycewicz J, Scibor Z, Cwikla JB, Lewinski A and Cypryk K: Recurrent hypoglycaemia in a type 2 diabetes patient-diagnostic difficulties. Arch Med Sci 6: 126-129, 2010.

29. Holstein A, Morgenstern T, Dienst H and Hiller W: Insulinoma as rare cause of severe post-partum hypoglycemia. J Obstet Gynaecol Res 41: 1848-1850, 2015.

30. Podzolkov VI, Dragomiretskaia NA, Koroleva TV, Kavtaradze NN, Iakovleva $\mathrm{HH}$ and Podzolkov AV: A rare case of hypoglycemia in an elderly patient with type 2 diabetes mellitus: Malignant metastasizing insulinoma. Klin Med (Mosk) 92 65-70, 2014 (In Russian).

31. Schmitt J, Boullu-Sanchis S, Moreau F, Drui S, Louis B, Chabrier G, Pinget $M$ and Jeandidier N: Association of malignant insulinoma and type 2 diabetes mellitus: A case report. Ann Endocrinol (Paris) 69: 69-72, 2008.

32. Siraj ES, Samuel G, Saber S, Samuel S, Hamrahian AH and Reddy SS: Metastatic malignant insulinoma in a patient with type 2 diabetes mellitus: Case presentation and literature review. Endocr Pract 12: 411-416, 2006.
33. Lei WY, Wang TE, Chen TL, Chang WH, Yang TL and Wang CY: Insulinoma causing hypoglycemia in a patient with type 2 diabetes. J Formos Med Assoc 106: 392-396, 2007.

34. Madathil A and Weaver J: Insulinoma presenting as postprandial hypoglycaemia. BMJ Case Rep 2011: 2011.

35. Shimizu M, Suzuki K, Tsuchida K, Kojima M, Hiraishi H and Aso Y: Insulinoma in a patient with chronic renal failure due to type 2 diabetes mellitus treated effectively with diazoxide. Intern Med 54: 621-625, 2015.

36. Wildbrett J, Nagel M, Theissig F, Gaertner HJ, Gromeier S, Fischer S and Hanefeld M: An unusual picture of insulinoma in type-2 diabetes mellitus and morbid obesity. Dtsch Med Wochenschr 124: 248-252, 1999 (In German).

37. Iglesias P and Diez JJ: Management of endocrine disease A clinical update on tumor-induced hypoglycemia. Eur J Endocrinol 170: R147-R157, 2014.

38. Levine RA and Sobel BE: Insulinoma, type 2 diabetes and plasminogen activator inhibitor type-I. Coron Artery Dis 12: $333-336,2001$. 